\title{
UMA REVISÃO DE FACE APLICADA A UM ESTUDO DE CASO
}

Roberta Fernandes Pacheco é professora adjunta da Universidade Federal de Juiz de Fora (UFJF), atuando no ensino de Língua Espanhola e na pesquisa com o projeto intitulado "Trabalhos de Face em situações de conflito: um estudo contrastivo entre o Português e o Espanhol”. Doutora em Linguística pela UFJF. E-mail: roberta.pacheco@ufjf.edu.br

\section{Resumo}

Este trabalho apresenta uma revisão teórica sobre o conceito de Face, sob a perspectiva interacional da Sociolinguística e da Pragmática, aplicando-o a um estudo de caso: uma entrevista, no ano de 2010, com o ex-ministro José Dirceu no programa Roda Viva, transmitido pela TV Cultura de São Paulo.

\section{Resumen}

Este trabajo presenta un repaso teórico sobre el concepto de Imagen, bajo la perspectiva interaccional de la Sociolingüística y de la Pragmática, aplicándolo a un estudio de caso: una entrevista, en el año 2010, con el ex ministro José Dirceu en el programa Roda Viva, propagado por la TV Cultura de São Paulo.

Um dos conceitos de face, sem dúvida, mais discutido e abordado nos estudos interacionais vem do trabalho de Goffman ([1955] 1980), acerca da natureza e forma de organização da interação social, em que face é definida como "o valor social positivo que uma pessoa efetivamente reclama para si mesma através daquilo que os outros presumem ser a linha por ela tomada durante um contato específico" (GOFFMAN, 1980, p.76-77). Linha, por sua vez, corresponde ao padrão de atos verbais e não-verbais que uma pessoa adota durante uma interação, expressando, assim, a avaliação que faz da situação em que se encontra engajada, dos demais participantes e, especialmente, de si mesma.

$\mathrm{Na}$ definição de Goffman, face é uma imagem social construída no fluxo dos eventos interacionais, podendo o indivíduo reivindicar diferentes faces, dependendo da situação, em um único contato específico. Além disso, a face depende da aceitação dos outros, pois é um construto social, um empréstimo feito pela sociedade ao indivíduo e que poderá ser-lhe retirada caso ele não se comporte de modo a merecê-la (GOFFMAN, 1967, p.10). Como Locher (2004) enfatiza, há um aspecto externalizado na visão de face de Goffman, que a considera "algo externo, que uma pessoa cria junto com seu ambiente" (LOCHER, 2004, p.52).

A origem do conceito de face em Goffman ([1955] 1980) remete ao estudo feito por $\mathrm{Hu}$ (1944) na sociedade chinesa, em que, baseado em um julgamento de conduta, face revela dois conjuntos de critérios, pelos quais prestígio é adquirido e status é garantido ou melhorado. Face, então, seria o conjunto de mien-tzu, que representa a reputação alcançada através do sucesso e da ostentação, e a lien, representando a confiança da sociedade na integridade do caráter moral do self. A perda da lien impede o indivíduo de funcionar adequadamente dentro da sociedade; é uma sanção social para impor padrões morais e ao mesmo tempo uma sanção internalizada.

Ao contrário da lien, a mien-tzu tem um caráter meritocrático e pode ser aumentada no decorrer da vida do indivíduo a partir da conduta do esforço pessoal. Como prestígio, este reconhecimento do self é dependente do ambiente externo, ou seja, é um reconhecimento pessoal, porém atribuído pela sociedade. Reivindicar mien-tzu é reclamar para si o mérito e o prestígio a que tem direito, devido a sua conquista pessoal e sua reputação social. 
Essa visão de face, definida como prestígio alcançado através da conduta do esforço pessoal, é exemplificada no corpus deste trabalho, já que o entrevistado José Dirceu reivindica face com base no mérito profissional que julga ter alcançado. A citação de seus papéis desempenhados na vida pública, apresentado no excerto abaixo, é uma tentativa de manter a sua face em um momento político que antecede seu julgamento no processo do "Mensalão", ou seja, um momento nada muito favorável ao entrevistado, já que ele era acusado de formação de quadrilha como o "chefe do Mensalão". Como este reconhecimento de prestígio do self é dado pela sociedade, Dirceu precisa aumentar sua face para restaurar sua imagem pública perdida. Note como os turnos do entrevistado são compostos basicamente de apresentação de self, baseada em seus papéis desempenhados ao longo de sua carreira política, em um caráter meritocrático da face. Os turnos de Dirceu são decorrentes do turno da entrevistadora Marília Gabriela, que o posiciona para a audiência e em seguida realiza as primeiras perguntas da entrevista:

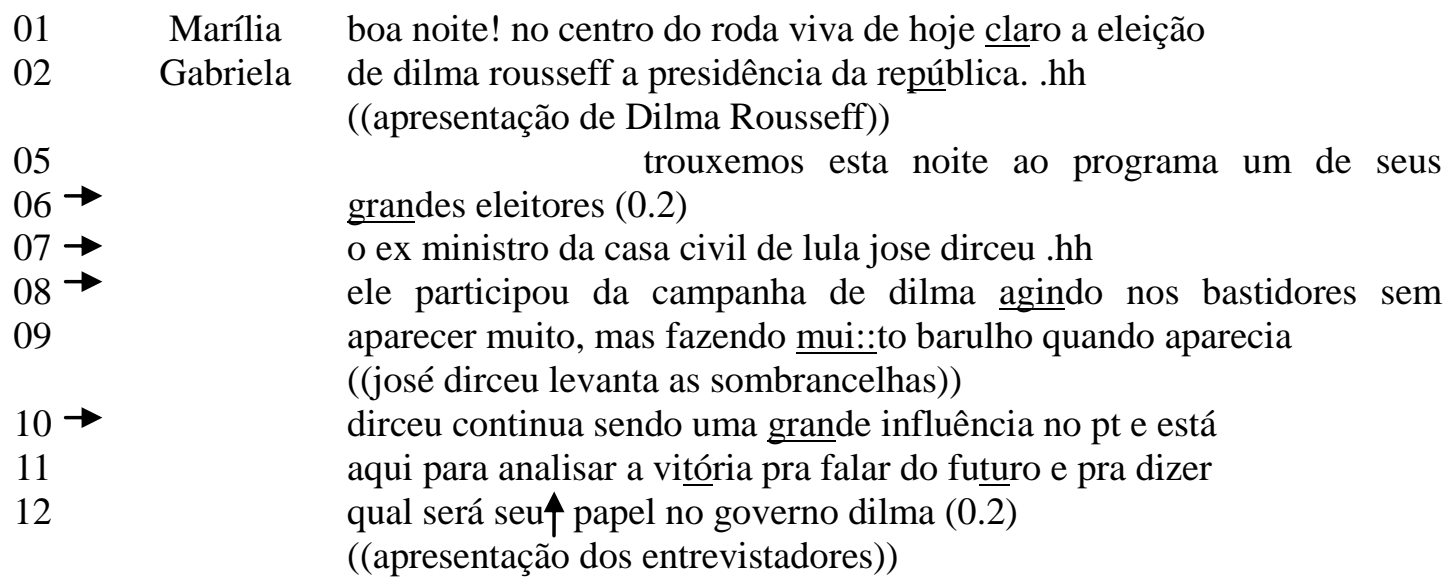

39 Marília OH nao adiantou na::da, estamos aí mais quatro anos (0.2)

40 Gabriela dois meses atrás você disse essa frase num discurso,

na bahia (0.2) e hoje você pode repeti-la quantas vezes

quiser, porque ela virou verdade, ne? o pt ta ai pra (0.2) mais quatro anos. e ontem, ao sair da cabine eleitoral, você declarou <não devo (0.2) não posso (0.2) e não quero ter cargo> no governo dilma (0.5) a minha pergunta é a seguinte, você ta gostando da sombra ze dirceu?, eu quero dizer, você prefere ser influente mas sem cargo?, e como é que você vai nos convencer de que você não vai participar mes::mo do governo dilma?

50 José $\quad$.hh não, eu não atuo nem nos bastidores, nem nas sombras,

51 Dirceu eu atuo abertamente e publicamente no país, aliás, sempre o fiz,eu fui cavalaria, patas de cavalaria, e depois de novo $>$ presidente $<$ da ue, (0.2) da >mesma maneira $<$ e fui eleito deputado estadual, >três vezes federal fui candidato a governador $<$,

fui ministro de estados, sempre publicamente. cassado pela câmara, 


\begin{tabular}{|c|c|c|}
\hline $\begin{array}{l}58 \\
59 \rightarrow \\
60\end{array}$ & & $\begin{array}{l}\text { <sem provas>. ( } 0.2) \\
\text { eu voltei a vida política como militante do pt, como cidadão } \\
\text { [eu tenho um blog-] }\end{array}$ \\
\hline 61 & $\begin{array}{c}\text { Marília } \\
\text { Gabriela }\end{array}$ & [mas na campanha] da dilma, você [ tava::] \\
\hline 62 & José & [eu atuei] como membro da \\
\hline $63 \rightarrow$ & Dirceu & direção nacional eu sou membro da direção nacional do pt \\
\hline 64 & & e atuei como tal. eu não era membro da coordenação mas \\
\hline 65 & & como membro da direção eu percorri o país (0.2) .hh \\
\hline 66 & & defendi o nome dela desde fevereiro de dois mil e oito (0.2) \\
\hline 67 & & e nove perdão. percorri o país, trabalhei pras alianças, \\
\hline 68 & & principalmente com o pmdb, com o >psb, pc do b e pdt<, \\
\hline 69 & & pelos palanques estaduais, que lhe deram a vitoria, ${ }^{\circ}$ muitos deles ${ }^{\circ}$ \\
\hline 70 & & foram fundamentais. e trabalhei também pra construir os discursos, as \\
\hline $71 \rightarrow$ & & propostas, porque sou. militante do $\mathrm{pt}$ \\
\hline $72 \rightarrow$ & & sou dirigente do pt, e no pt fiz esse trabalho. não tenho participação \\
\hline 73 & & (0.2) direta na coordenação e não terei no governo. (0.2) como eu disse \\
\hline 74 & & e quero repetir $(0.2)$ \\
\hline 75 & & >não devo não quero e não posso< eu tenho primeiro que (0.2) \\
\hline $76 \rightarrow$ & & $>$ prestar contas a justiça< já que eu estou sendo acusado no supremo \\
\hline 77 & & tribunal federal, de chefe de quadrilha \\
\hline $78 \rightarrow$ & & e de corrupção, não é pouca coisa. (0.2) \\
\hline $79 \rightarrow$ & & como eu sou inocente $(0.5)$ \\
\hline & & ((Dirceu aponta para si, corroborando a fala de inocente) $)$ \\
\hline 80 & & e nesses anos todos (0.2) todas as investigações inquéritos processos \\
\hline 81 & & cpis que eu respondi eu fui absolvido inclusive na justiça, federal já fui \\
\hline 82 & & absolvido duas vezes $(0.2)$ \\
\hline
\end{tabular}

No excerto acima, notamos que a ameaça à face de Dirceu ocorre já no início da entrevista quando Marília Gabriela o apresenta como alguém que atua "nos bastidores" (1. 8) e "nas sombras" (1. 46). Tal ameaça é reconhecida pelo entrevistado que na busca por manter sua face, refuta esses atributos nas linhas 50 e 51 "eu não atuo nem nos bastidores nem nas sombras. Eu atuo abertamente e publicamente no país, aliás sempre o fiz". Ele refuta esse posicionamento porque o considera de valor negativo, pois atuar nos bastidores e nas sombras passa uma ideia de ilegalidade, atuar às escondidas. Dessa forma, ele justifica a negação desses atributos na sequência dos turnos, destacando seu histórico de vida política.

Manter a face, perdê-la ou salvá-la envolvem processos elaborados de trabalhos de face, que, de acordo com Goffman ([1955] 1980), são ações realizadas pelos interagentes para tornar o que quer que estejam fazendo consistente com a face que está sendo reivindicada num dado momento (GOFFMAN, 1967, p.5). Para Dirceu, apresentar seu histórico político é uma forma de manter face diante de uma potencial perda de face, ameaçada pela entrevistadora quando o enquadra como um político atuando às escondidas.

Goffman ([1955] 1980; 1967) defende a existência de duas principais orientações de trabalhos de face: orientação protetora e defensiva da face. Mediante a orientação protetora, o indivíduo procura salvar a face dos outros, porém tal ação deve ser feita de 
uma forma que não leve à perda da sua própria face. Na orientação defensiva, o indivíduo busca salvar sua própria face, o que também deve ser feito com cuidado, pois é importante considerar a perda da face que esta ação pode acarretar nos outros. É a metáfora da balança, em que o equilíbrio entre os pesos é fundamental para que ela se mantenha. Na interação, salvar a sua face sem que leve à perda da face do outro exige um esforço entre os participantes envolvidos para manter o equilíbrio do encontro.

Sendo assim, as interações humanas nessa perspectiva seriam então orientadas e regulamentadas por uma preocupação que os interlocutores têm com suas faces e com as faces dos outros. Haveria, contudo, situações em que o indivíduo, por escolha de uma linha inadequada ou pela introdução de elementos alheios à sua vontade, se veria fora de face ou na face errada, situações estas que produziriam, por sua vez, sentimentos de embaraço, vergonha, inferioridade, confusão (GOFFMAN, 1980, p.79). Estas são algumas das situações que Goffman enquadra como envolvendo ameaças à face, e que dão origem a uma sequência de atos reparadores, que visariam salvar a face do indivíduo.

Os atos reparadores a uma possível ameaça à face tiveram um espaço de relevância nos estudos da teoria da polidez de Brown e Levinson ([1978] 1987). Os autores se basearam no conceito de face de Goffman para construir uma teoria em que as estratégias de polidez são utilizadas como reparadoras desses atos. No entanto, a definição de face dos autores tem o foco nos desejos do indivíduo, o que não ocorre na definição de Goffman. A face então seria "a imagem pública que cada membro [de uma dada sociedade] quer reivindicar para si” (BROWN e LEVINSON, [1978] 1987, p.61). Dessa forma, o indivíduo tem duas necessidades básicas de face: o desejo de ser aprovado pelo outro - face positiva - e o desejo de não sofrer imposição em suas ações - face negativa.

Como discute Bousfield (2008), citando Locher (2004) e O’Driscoll (1996), nessa definição de Brown e Levinson ([1978] 1987), a face não é ameaçada em termos de norma ou valores sociais, como em Goffman ([1955] 1980), e sim em relação a uma necessidade básica do indivíduo, ou seja, os processos que envolvem a face - sua perda, salvamento ou ameaças - giram em torno de desejos individuais, necessidades internas do indivíduo, e que seriam pré-existentes à interação. A face seria um princípio internamente gerado e individualista, enquanto para Goffman, a face é uma imagem reivindicada socialmente e concedida a partir do exterior, na relação com o outro.

Essa discussão entre o aspecto internalizado e externalizado da face vem ocupando espaço nas teorias atuais, principalmente no que concerne aos estudos da polidez/impolidez. Terkourafi (2008), por exemplo, rejeita o aspecto internalizado da face, defendendo que a face é constituída ou ameaçada puramente na interação: "sem um Outro para estar direcionada, a preocupação com a face não pode emergir" (op. cit., p.52). Como Bousfield destaca:

estamos nos afastando de uma visão de face clássica (Brown e Levinson) estática, préexistente, que é ameaçada, danificada, reparada ou enaltecida e que é internamente gerada e projetada pelo indivíduo no espaço interacional entre os participantes, para 
uma consideração de face mais fluida, em que o conceito é dinâmico e móvel, e é criada, fortalecida ou enfraquecida na (frequentemente estendida) interação.

(BOUSFIELD, 2008, p.39)

Com “estamos", Bousfield (2008, p.39) se inclui nessa discussão em que se reconsidera utilizar como ponto de partida a noção de face de Goffman em vez de a de Brown e Levinson, principalmente quanto ao aspecto de "propriedade pública" (KEDT, 1998), ou seja, como algo realizado na interação e dependente dos outros. O autor, no entanto, não comunga totalmente da posição de Terkourafi (2008), de que a face é somente negociada no encontro social, uma vez que não concorda que o interagente "não traz alguma coisa a respeito de suas próprias faces para a interação. Certamente nós abordamos a interação com expectativas de como gostaríamos que nossas faces fossem constituídas" (BOUSFIELD, 2008, p.39). Como essas expectativas são organizadas internamente, Bousfield (op.cit.) considera que a face também possui um aspecto interno, além do externo que é elaborado no processo interacional. Portanto, a definição de face do autor engloba os dois aspectos, sendo face "esperada individualmente (internamente, cognitivamente, historicamente) pelo self, mas constituída interacionalmente (externamente, mutuamente, continuamente) entre o self e o outro" (BOUSFIELD, 2008, p.42).

Spencer-Oatey $(2007,2009)$ compartilha também dessa visão cognitiva e interacional da face. No entanto, sua abordagem parte de uma perspectiva identitária, na qual os atributos da representação do self que emergem no encontro são considerados cruciais para o estudo interacional da face.

A autora argumenta que apesar de muitos autores (LIM, 1994; ARUNDALE, 2005) colocarem em lados opostos os conceitos de identidade e face, considerando que a primeira é de natureza individual e a segunda um fenômeno relacional, ambas podem estar mais interligadas no processo interacional do que se tem acreditado até então.

Spencer-Oatey (2007, p.644) propõe que, em termos cognitivos, face e identidade são similares já que ambas remetem para a noção de autoimagem (incluindo interpretações do self individual, relacional e coletivo) e sustentam múltiplos aspectos do self ou atributos. No entanto, face só é associada a atributos que são afetivamente sensíveis para o requerente. Por isso que, segundo a autora, a face é associada a atributos avaliados positivamente que o requerente quer que os outros reconheçam (explicitamente ou implicitamente) e a atributos avaliados negativamente que o requerente não quer que os outros atribuam a ele. Dessa forma, a autora relaciona face a uma "sensibilidade afetiva" (op. cit.) que o indivíduo possui e que o leva a reivindicar face a partir do que ele considera como um atributo social aprovado. A sensibilidade afetiva, então, como um aspecto da face, a torna um fenômeno vulnerável e associado a reações emocionais, geradas por valores afetivos culturais e socialmente aprovados.

Spencer-Oatey (2007, p.643-644) ainda propõe que esses atributos afetivamente sensíveis variarão dinamicamente na interação, e nem sempre de acordo com o que é socialmente sancionado - ou não-sancionado, no caso dos traços avaliados negativamente. De fato, é possível que as pessoas escolham contestar um ou mais 
atributos aprovados, e reivindicar outros atributos que são mais importantes para eles em um contexto particular. Além disso, interacionalmente, a ameaça, a perda e/ou o ganho de face só serão percebidos quando houver uma incompatibilidade entre um atributo reivindicado - ou negado, no caso dos traços avaliados negativamente - e um atributo percebido como sendo atribuído pelo outro.

O exemplo a seguir, apresentado em Spencer-Oatey (2007), demonstra a importância de considerar a variedade dos diferentes atributos que podem se tornar sensíveis à face em um encontro particular:

Uma senhora britânica, em torno dos seus 50 anos, ajudou a um jovem estudante húngaro com dificuldades na língua inglesa a encontrar o caminho certo para pegar o trem em Londres, em direção ao aeroporto de Luton. Ao chegar o trem, a seguinte interação tomou lugar:

Estudante húngaro: Muito obrigado. Você é uma senhora idosa muito amável.

Senhora britânica: Não tem problema. Eu ia pegar este trem de qualquer maneira. (SPENCER-OATEY, 2007, p.645).

Neste exemplo, Spencer-Oatey (op.cit.) retrata uma experiência pessoal, na qual a senhora britânica - a própria autora - ao ajudar um jovem estrangeiro, recebe de agradecimento um elogio: Você é uma senhora idosa muito amável. Contudo, SpencerOatey, apesar de responder gentilmente ao jovem, não reconhece esta elocução como um elogio de fato, pelo menos não em sua totalidade, já que o atributo senhora idosa não funciona para ela como um elogio, pois Spencer-Oatey se vê como uma mulher de meia idade e não idosa: "Eu estava agradecida porque ele me avaliou como muito amável, e isso manteve ou até intensificou minha face; por outro lado, eu me considero na 'meia-idade' e não 'velha', e então isto ameaçou minha face” (op. cit.).

Nota-se como, no exemplo e na justificativa da autora, o atributo pessoal reivindicado por ela não é o mesmo atribuído por seu interlocutor e é exatamente essa oposição entre o que é reivindicado e o que é atribuído que gera a ameaça à face, em seu julgamento avaliativo em relação a essas qualidades (valor positivo para amabilidade; valor negativo para velhice). Para Spencer-Oatey (2007, 2009) a ameaça à face é percebida quando há incompatibilidade entre o atributo reivindicado - mulher de meia idade - e o atributo dado - senhora idosa. Já o atributo muito amável dado pelo jovem é avaliado pela autora sem ser ameaçador a sua face, uma vez que é percebido afetivamente como um elogio, um atributo positivo "que o requerente quer que os outros reconheçam" (Spencer-Oatey, 2007, p.644). Além disso, é um atributo também reivindicado por ela na interação, sendo então avaliado como um aumento de face.

$\mathrm{Na}$ entrevista, que compõe o corpus deste artigo, também há exemplos em que a incompatibilidade entre o atributo dado e o reivindicado gera uma ameaça à face que é percebida pelos participantes envolvidos na interação. O excerto abaixo se inicia em um momento da entrevista em que se discute a política externa do governo Lula e as possíveis falhas nestes acordos internacionais, como a proximidade com o Irã, com Cuba e a questão dos presos políticos. José Dirceu, o entrevistado, defende o governo em relação a essas relações vistas como problemáticas, enquanto os entrevistadores 
contestam essa defesa, até o momento em que José Dirceu assume que de fato é "amigo de cuba" - linha 252 -, o que não significa que concorde com tudo o que Cuba decide politicamente - linhas 255 e 256. A exemplificação abaixo parte exatamente deste ponto, em que participam os entrevistadores Marília Gabriela e Paulo Moreira Leite:

\begin{tabular}{|c|c|c|c|}
\hline 252 & Dirceu & & hhh eu sou amigo de [cuba mesmo \\
\hline 253 & Paulo & & [ ${ }^{\circ}$ pois é, então: ${ }^{\circ}$ \\
\hline 254 & Marília & & [[O:: ZÉ \\
\hline $\begin{array}{l}255 \\
256\end{array}$ & Dirceu & & $\begin{array}{l}\text { [[isso não quer dizer que eu concorde com tudo que acontece em } \\
\text { cuba= }\end{array}$ \\
\hline 257 & Marília & & $=\mathrm{O}::$ ZÉ! $=$ \\
\hline 258 & Dirceu & & $=$ até porque eu tenho uma história, né?= \\
\hline 259 & Marília & $\rightarrow$ & =você é lobista hoje! é isso? \\
\hline 260 & Dirceu & $\rightarrow$ & não. não sou. \\
\hline 261 & Marília & $\rightarrow$ & você, você faz business. \\
\hline 262 & Dirceu & $\rightarrow$ & ${ }^{\circ}$ não ${ }^{\circ}$. não faço. faço consultor. sou advogado. \\
\hline 263 & & & porque que os outros $\uparrow$ consultores não são lobistas e eu sou? \\
\hline 264 & Marília & & [[não! tá bom \\
\hline 265 & Dirceu & & {$\left[\left[\operatorname{diz}\right.\right.$ pra $\operatorname{mim}\left[{ }^{\circ}\right.$ isso $\left.^{\circ}\right]$} \\
\hline 266 & Marília & & [ não ] porque é- \\
\hline 267 & Dirceu & & não. é uma [coisa] \\
\hline 268 & Marília & $\rightarrow$ & [não é] uma profissão? existe uma profissão= \\
\hline 269 & Dirceu & $\rightarrow$ & =não! no brasil- lobista tem um caráter, de tráfico de influências. \\
\hline 270 & Marília & & bom- \\
\hline 271 & Dirceu & $\rightarrow$ & tem um caráter pejorativo e quase criminoso. \\
\hline 272 & & $\rightarrow$ & eu sou advogado e consultor! \\
\hline 273 & Paulo & & tá. >eu justamente queria perguntar isso< $(0,2)$ \\
\hline 274 & & & $>$ dirceu $<$, eu conheço gente que se emocionava ao sair de casa, \\
\hline 275 & & & em 68 pra ver você fazer discurso no cento de são paulo. bombas \\
\hline 276 & & & $>$ etc etc $<$ muita gente que ficou feliz quando vocề voltou: \\
\hline 277 & & & muita gente que teve identificação com você da sua luta política \\
\hline 278 & & & $>$ dessas suas ideias e tudo $<$ \\
\hline 279 & & & hoje essas pessoas, perguntam assim, \\
\hline 280 & & & como é que o zé dirceu ganha a vida? \\
\hline 281 & Dirceu & & trabalhando. igual [você ganha] \\
\hline 282 & Paulo & & [aí fica uma] coisa com[ plica::da ] \\
\hline 283 & Dirceu & & [não! igual] você ganha \\
\hline 284 & Paulo & & [[não. eu ganho \\
\hline 285 & Dirceu & & [[igualzinho \\
\hline 286 & Paulo & & todo mundo sabe onde eu traba::lho= \\
\hline 287 & Dirceu & & $=\mathrm{e}$ todo mundo sabe onde eu tra [ balho ] \\
\hline 288 & Paulo & & [não não] \\
\hline 289 & & & quais são os seus- as pessoas não sabem quais os seus clientes. \\
\hline 290 & Dirceu & & [[não, o:: paulo moreira leite! \\
\hline 291 & Paulo & & [[as pessoas não sabem \\
\hline 292 & Dirceu & & o:: paulo moreira leite! \\
\hline 293 & Paulo & & exatamente. \\
\hline 294 & Dirceu & & $\begin{array}{l}\text { você pergunta pros outros consultores quais são os clientes } \\
\text { deles? }\end{array}$ \\
\hline 295 & Paulo & & não. AÍ é que tá! você não é um consultor. você tem uma \\
\hline
\end{tabular}


biografia e- de repente, a sua biografia, ela tá in- tá diferente.

ela tá es [tranha]

[não tá ] nada de diferente! eu sou advogado e consultor.

Marília mas você é um consultor privilegiado! você tem=

Dirceu =quer dizer que eu não posso trabalhar pra

levar [investimentos brasileiros ]

Paulo [claro que po::de trabalhar]

Dirceu

Paulo

pro exterior pro peru pra [colômbia]

Dirceu

[claro que] po::de

Paulo

Dirceu

pra europa eu não posso trazer investimentos pro brasil?

o que as pessoas querem saber como um homem público=

=como um homem público me CASSARAM me tiraram do governo

queriam me [banir de dentro do país]

Marília [mas você ainda influi::]

mas você ainda é um homem influente nesse partido e neste poder

Dirceu eu sou influente? não tenho nenhuma [incompatibilidade com]

$\begin{array}{ll}\text { Marília } & \longrightarrow \\ \text { Dirceu } & \longrightarrow \text { fazer [ loby tendo essa influência? ] } \\ & \longrightarrow \text { [eu não faço loby! você que tá] dizendo que eu faço } \\ \text { Marília } & \longrightarrow \text { [OH MẼo faço loby ] } \\ \text { Dirceu } & \longrightarrow \text { faço consultoria! }\end{array}$

No excerto acima, Marília Gabriela atribui a José Dirceu a função de lobista na linha 259, enfatizando-a na linha 261. No entanto tal atributo é negado por José Dirceu, uma vez que ele não o reivindica por considerá-lo como tendo "um caráter de tráfico de influências" - linha 269 - e "pejorativo e quase criminoso" - linha 271 -, ou seja, é um atributo que possui um julgamento avaliativo de valor negativo, portanto não sendo legitimado pelo entrevistado. Essa negação do atributo dado gera os outros embates na sequência de turnos em relação à ocupação do ex-ministro: consultor ou lobista? José Dirceu reivindica face neste excerto, através do atributo de consultor, que negocia investimentos no Brasil - linhas 301 e 305 -, sendo um atributo de valor positivo, enquanto nega a função de lobista - linhas 312 a 317 - que lhe ameaça à face, pois em sua avaliação, é um atributo de valor negativo.

A proposta de Spencer-Oatey para a conceptualização de face tem base nas teorias sobre a identidade na psicologia social. Estas teorias defendem que a identidade não só incorpora representações individuais do self, mas também representações relacionais e coletivas.

Segundo Brewer e Gardner (1996), os três níveis de representação do self individual, interpessoal e de grupo - devem ser distinguidos ao se abordar a identidade. No nível individual há o self pessoal que representa o diferenciado e individualizado conceito do self. No nível de grupo, há um self coletivo que representa o conceito de self derivado do que é significante para os membros do grupo. Já no nível interpessoal, há o self relacional, que representa o conceito do self derivado das conexões e relações de papéis relevantes para os outros.

Os níveis de representação do self de grupo e interpessoal são distinções, segundo 
Brewer e Gardner (1996), de um self social que reflete a assimilação com os outros ou com os grupos relevantes ao self pessoal, criando identidades coletivas, no nível do grupo, e identidades interpessoais. Ambas identidades diferem em termos de suas conexões sociais, se estas são laços de ligação personalizados - identidade interpessoal - ou impessoais: identidade coletiva. Os laços de ligação impessoais são derivados da identificação comum com algum grupo simbólico ou alguma categoria social, contudo, sem requerer relações pessoais entre os membros do grupo. Já os laços personalizados derivam de relações diádicas íntimas, mas também das relações face-a-face de grupos pequenos que são essencialmente redes de tais relações diádicas.

A identidade social, então, implica um sentido despersonalizado do self; "implica uma mudança em direção à percepção do self como um exemplar intercambiável de alguma categoria social, fora da percepção do self como uma única pessoa" (TURNER et. al, 1987, p.50). A ideia desse self socialmente expandido vai além das conexões relacionais entre o self e o outro. Significa para Brewer e Gardner (1996) que as fronteiras do self são redesenhadas, e seu conteúdo é focado naquelas características que fazem de uma pessoa um bom representante de grupo ou de uma relação. Quando as identidades coletivas são ativadas (BREWER, 1991), os aspectos mais relevantes do conceito do self se tornam aqueles que são partilhados com os outros membros do grupo. Similarmente, nas relações interpessoais, as características do self, sejam cognitivas e/ou motivacionais, são ativadas operacionalmente na inclusão do outro, envolvendo uma indefinição dessas fronteiras entre o self e o outro.

Esses processos de categorização afetivos e cognitivos que envolvem a identidade social - de grupo e interpessoal - foram também relevantes na teoria de Simon (2004). No entanto, o autor abrange também o nível individual do self, considerando esses três níveis de representação do self de natureza cognitiva e social. Segundo o autor, as pessoas formam representações cognitivas de quem são e constroem/negociam suas identidades através da interação social. Elas não só apresentam elementos de seus selves pessoais, interpessoais e coletivos, através do processo interacional, como também os negociam/constroem com as outras identidades que se desenvolvem e emergem no contato com o outro.

Tanto a teoria de Simon (2004) quanto a de Brewer e Gardner (1996) dão suporte a Spencer-Oatey $(2007,2009)$ em sua definição de face. A autora, contudo, também recorre a Schlenker e Pontari (2000) em sua teoria do gerenciamento de impressão e da apresentação do self. Enquanto esta última é um termo que se refere ao controle de informação sobre o self, o gerenciamento de impressão é definido como a atividade meta-direcionada de controle de informação sobre o outro. Segundo os autores, as pessoas tentam controlar informação sobre elas próprias, amigos, inimigos, ideais e eventos, como as atividades em que estão engajadas.

Essa atividade meta-direcionada de controle de informação do self e do outro, segundo Schlenker e Pontari (2000), é relevante em toda interação social e não só naquelas situações em que há um alto processo avaliativo em jogo, como as entrevistas de emprego, por exemplo. Esse controle de informação perpassa o aspecto motivacional que Brewer e Gardner (1996) relacionam como um dos aspectos do self. Para estes 
autores os motivos derivados do interesse do self pessoal são diferentes dos derivados da preocupação com o interesse dos outros (MCCLINTOCK, 1972). As relações interdependentes, por exemplo, como enfatizam Markus e Kitayama (1991) e Baumeister e Leary (1995), são caracterizadas por preocupações mútuas com os interesses e resultados dos outros. Bateson (1994) definiu esta preocupação como a base da motivação altruísta, que segundo ele não deve ser confundida com o sacrifício do self, que lhe causa custos, mas com a motivação de beneficiar o outro.

Brewer (1991) defende que "quando a definição do self muda, o significado da motivação do interesse do self e do atendimento do self também mudam na mesma proporção" (BREWER, 1991, p.476). Isto é, a motivação social, de acordo com Brewer e Gardner (1996), é outra importante transformação associada a diferentes níveis de construção do self que envolve uma mudança nas metas básicas da interação social.

Essa motivação social determina cada nível de categorização do self. No nível do self pessoal, os indivíduos procuram similaridade com os outros, mas ao mesmo tempo lutam por um sentido de singularidade. O self relacional frequentemente é caracterizado em termos da tensão entre separação e intimidade com os outros. Já as identidades coletivas são restringidas pela necessidade de satisfazer necessidades individuais de inclusão e de diferenciação.

Em cada nível de representação do self, essas forças opostas de assimilação e diferenciação criam um equilíbrio dinâmico que flutua com as mudanças na distância entre o self e os outros. Para Brewer e Gardner (1996), uma explicação dinâmica similar pode explicar a mudança entre níveis de categorização do self. Quando necessidades de intimidade no nível interpessoal não são atendidas, identidades coletivas podem se tornar mais importantes; períodos prolongados de imersão em um coletivo despersonalizado podem aumentar a importância de reconhecimento do self pessoal, individualizado, e assim por diante.

Essa conceptualização de identidade social e pessoal nas representações do self interacional é relevante para a definição de face de Spencer-Oatey (2007, 2009):

Face é um fenômeno complexo que precisa ser estudado a partir de múltiplas perspectivas. Teorias da identidade sugerem que a face tem um número de características que precisam ser mantidas em uma balança dialética:

- face é um fenômeno multi-facetado, mas pode também ser um conceito unitário

- face tem fundações cognitivas e é também socialmente constituída na interação

- face 'pertence' ao indivíduo e ao coletivo, e também se aplica às relações interpessoais.

(SPENCER-OATEY, 2007, p.654)

É esta perspectiva dialética da definição de face de Spencer-Oatey (op.cit.) que considero relevante aos estudos interacionais sobre o conceito. Considero que analisar a face é considerar as expectativas/motivações e valores que os interagentes carregam em suas apresentações do self e negociam com as outras representações trazidas pelos outros participantes no processo interacional em curso. Essas representações podem operar no primeiro ou no segundo plano, ou seja, à vista de todos na interação ou no pano de fundo das inter-ações dos interagentes, porém nunca estarão ausentes neste 
processo.

\section{Referências}

ARUNDALE, Robert. B. Face as relational and interactional: alternative bases for research on face, facework, and politeness. Paper presented at the 9th International Pragmatics Association Conference, Riva del Garda, Italy, 10-15 July, 2005.

BATESON, C. D. Why act for the public good? Four answers. Personality and Social Psychology Bulletin. 20, 603-610, 1994.

BAUMEISTER, R. F.; LEARY, M. R. The need to belong: desire for interpersonal attachments as a fundamental human motivation. Psychological Bulletin. 117, 497$529,1995$.

BOUSFIELD, Derek. Face within a model of im/politeness. In.:

Impoliteness in Interaction. Cap.3, p. 33-42, vol. 167. John Benjamins Publishing Company. Amsterdam/ Philadelphia, 2008.

BREWER, Marilyn, B. The social self: on being the same and different at the same time. Personality and Social Psychology Bulletin. 17, 475-482, 1991.

; GARDNER, Wendi. Who is this "we"? Levels of collective identity and self representations. Journal of Personality and Social Psychology. 71 (1), 83-93, 1996.

BROWM, Penélope; LEVINSON, Stephen. Politeness some universal in language usage. Cambridge, Cambridge University Press, [1978] 1987.

GOFFMAN, Erving. Interactional ritual: Essays on face-to-face interaction. Garden City, NY: Doubleday, 1967.

A Elaboração da Face: Uma Análise dos Elementos Rituais da Interação Social. In.: FIGUEIRA, S. (org.). Psicanálise e Ciências Sociais. Rio de Janeiro: Livraria Francisco Alves [on Face-work: An analysis of ritual elements in social interaction. Psychiatry, 18, 213-231, 1955], 1980.

HU, H. C. The Chinese Concepts of "Face". American Anthropologist. New Series, vol. 46, No 1, part 1, p. 45-64, 1944. 
KEDT, E. The concept of face and its applicability to the Zulu language. Journal of Pragmatics. 29: 173-191, 1998.

LIM, Tae-Sop. Facework and interpersonal relationships. In: Ting-Toomey, S. (Ed.). The Challenge of Facework. State University of New York Press, New York, p. 209229, 1994.

LOCHER, Miriam. Power and Politeness in Action Disagreements in Oral Communication. Mounton de Gruyter, Berlin, Nova York, 2004.

MARKUS, H.; KITAYAMA, S. Culture and the self: Implications for cognition, emotion, and motivation. Psychological Review. 98, 224-253, 1991.

McCLINTOCK, C. G. Social motives: A set of propositions. Behavioral Science.17, 438-454, 1972.

O'DRISCOLL, Jim. About face: a defense and elaboration of universal dualism. Journal of Pragmatics. 25 (1), 1-32, 1996.

SCHLENKER, Barry; PONTARI, Beth. The strategic control of information: impression management and self-presentation in daily life. In: TESSER, A., FELSON, R.B., SULS, J.M. (eds.). Psychological Perspectives on Self and Identity. American Psychological Association, Washington, pp. 199-232, 2000.

SIMON, Bernd. Identity in Modern Society. A Social Psychological Perspective. Blackwell, Oxford, 2004.

SPENCER-OATEY, Helen. Theories of identity and the analysis of face. Journal of Pragmatics 39. p.639-656, 2007.

Face, identity and interactional goals. In.: BARGIELACHIAPPINI, Francesca; HAUGH, Michael. Face, Communication and Social Interaction. London, Oakville:Equinox, p.137-154, 2009.

TERKOURAFI, Marina. Toward a unified theory of politeness, impoliteness, and rudeness. In.: BOUSFIELD, Derek; LOCHER, Miriam (eds.). Impoliteness in Language. Studies on its Interplay with Power in Theory and Practice. Cap. 3, 45-74, Mouton de Gruyter, 2008. 
TURNER, J. C.; HOGG, M.; OAKES, P.; REICHER, S.; WETHERELL, M. Rediscovering the social group: A self-categorization theory. Oxford, England: Basil Blackwell, 1987. 


\section{Anexos}

Convenções de Transcrição

pausa não medida

pausa em décimos de segundo, medida relativamente ao ritmo prosódico do segmento no qual se encontra inserida.

? entonação descendente ou final de elocução

entonação ascendente

entonação de continuidade

parada súbita

$=$

palavra

MAIÚSCULA

!

${ }^{\circ}$ palavra ${ }^{\circ}$

$>$ palavra $<$

$<$ palavra $>$

: ou ::

[

]

[ ]

[[

$(\quad)$

(palavra)

$((\quad))$

"palavra"

$\uparrow$

$\downarrow$

hh

elocuções contíguas, enunciadas sem pausa entre elas

(engatamento)

ênfase (parte da sílaba e/ou palavra)

ênfase mais forte ou fala em voz alta

tom animado, não necessariamente exclamativo.

fala em voz baixa

fala mais rápida

fala mais lenta

alongamentos

início de sobreposição de falas

final de sobreposição de falas

colchete abrindo e fechando o ponto da sobreposição, com

marcação nos segmentos sobrepostos - sobreposições localizadas

colchetes duplos no início do turno simultâneo (quando dois falantes iniciam o mesmo turno juntos)

fala não compreendida

fala duvidosa

comentário do analista: descrição de atividade não verbal (riso, tosse, atitude, expressão face, gestos, ruídos do meio ambiente, dentre outros)

fala relatada

subida de entonação (mudança de entonação)

descida de entonação (mudança de entonação)

aspiração (em parêntesis qdo no meio de palavra)

.hh

inspiração (em parêntesis qdo no meio de palavra)

hhh

riso (em parêntesis qdo no meio de palavra) 